\title{
Prevalence and antimicrobial susceptibility of respiratory pathogens in patients with cystic fibrosis
}

\section{Authors}

Vilma Almeida Paixão ${ }^{1,2}$ Tânia Fraga Barros ${ }^{2}$ Clélia Maria C Mota ${ }^{1,2}$

Tamy Fagundes Moreira² Maria Angélica Santana ${ }^{1}$ Joice Neves Reis ${ }^{2}$

${ }^{1}$ Secretary of Health of Bahia State, Brazil; Hospital Especializado Otávio Mangabeira, Bahia, Brazil. ${ }^{2}$ Postgraduation in Microbiology; Department of Clinical and

Toxicological Analysis, Pharmacy School,

Universidade Federal da Bahia, Brazil.
Submitted on: 07/28/2009 Approved on: 11/17/2009

Correspondence to: Vilma Almeida Paixão Rua das Gaivotas, no. 128 BL- C, Apto 1503, Imbuí, Salvador -

Bahia - Brazil

CEP: 41720-070

Phone: $+55-71-32312078$

Phone(Fax):

+55-71-32372255

E-mail: vvilmapaixao@ gmail.com

We declare no conflict of interest.

\begin{abstract}
Respiratory infection is very common in patients suffering from cystic fibrosis (CF). However, the antimicrobial resistance rate of isolates from CF patients is not often documented. In this study, 279 respiratory specimens of 146 patients were prospectively collected from July to December 2006. Microbiological cultures and antimicrobial susceptibility tests of the most frequently isolated bacteria were performed. Sputum and oropharyngeal swabs were processed for culture. During the study period, 50\% of the patients harbored Staphylococcus aureus, 35\% Pseudomonas aeruginosa, 4.7\% Haemophilus influenzae. Methicillin resistant S. aureus (MRSA) were detected in 8 (6\%) patients; ESBL and MBL-producing $P$. aeruginosa were not identified in these patients. The detection of MRSA in CF patients confirms that antimicrobial resistance patterns should be always kept under surveillance. Moreover, hygiene regulations in CF clinics should prevent a further spread of resistant bacterial strains.
\end{abstract}

Keywords: cystic fibrosis, antimicrobial resistance, Pseudomonas aeruginosa, Staphylococcus aureus. [Braz J Infect Dis 2010;14(4):406-409] CElsevier Editora Ltda.

\section{BACKGROUND}

The main feature of cystic fibrosis (CF) is chronic respiratory infection, which may start very early in the life of these patients. Since the early description of CF, pulmonary infection has been recognized as playing the greatest role in morbidity and mortality leading to premature death in $90 \%$ of patients. ${ }^{1}$ Impairment of the muco-ciliary transport and thus the cleaning function of the upper airway predisposes for bacterial colonization and chronic infections by Staphylococcus aureus and Pseudomonas aeruginosa. ${ }^{1,2}$ Subsequently, the microbiology of CF becomes more complex when other non-fermenting Gram-negative organisms, such as members of the Burkholderia cepaciacomplex ensue and Pseudomonas aeruginosa switch to the mucoid phenotype, which is more difficult to eradicate. ${ }^{3,4}$

Increase in multidrug-resistance in Gramnegative pathogens such as Pseudomonas aeruginosa and Burkholderia cepacia complex makes the therapeutic management of CF patients more complex since the therapeutic options are very limited. ${ }^{5}$ Thus, careful isola- tion and identification, and accurate studies of susceptibility to antibiotics are critical for predicting the spread of strains, improving therapeutic measures and facilitating our understanding of the epidemiology of these pathogens. The aim of this study was to determine the prevalence of pathogens isolated from respiratory samples of CF patients receiving care at the Referral Cystic Fibrosis Center of Bahia, and to evaluate the spectrum of antimicrobial-resistance of these organisms.

\section{METHODS}

\section{Patients and samples}

A clinical laboratory study including $146 \mathrm{pa}-$ tients attending regularly the Referral Center for Cystic Fibrosis of Bahia, Hospital Otavio Mangabeira, between July and December 2006 was conducted. The diagnosis of CF was confirmed according to the criteria of the Cystic Fibrosis Foundation. ${ }^{6}$ Spontaneous and induced sputum samples and oropharyngeal swabs were obtained for each patient during periods of clinical stability at regular clinical 
and physiotherapy attendance was performed every three months. Patients with history of antibiotic therapy in the last 90 days were excluded.

\section{Processing of sputum samples and culture of organisms}

Spontaneous sputum samples obtained from all patients involved during the study period were mixed with equal volumes of $1 \%$ dithiothreitol (Merck, Germany) before incubation at $37^{\circ} \mathrm{C}$ for $30 \mathrm{~min}$. When it was not possible to obtain spontaneous sputum samples, an oropharyngeal swab was used as a sample. All specimens were examined microscopically and cultured in agar blood, agar chocolate, MacConkey agar, Mannitol Salt Agar, and Burkholderia cepacea agar (BCSA) incubated for a period of 18 to 48 hours at $36^{\circ} \mathrm{C}$, followed by room temperature incubation for up to 72 hours. All isolates obtained from the samples were identified by the autoSCAN-4 (Dade Behring, Inc., West Sacramento, CA, USA). Preparation of suspensions, inoculations, incubation times, temperatures, and interpretation of reactions were performed according to the manufacturer's instructions. Additional biochemical tests for bacterial identification were performed whenever necessary.

\section{Antimicrobial susceptibility testing}

Susceptibility testing of all bacterial strains was carried out through broth microdilution assay using an automated autoSCAN-4 system (Dade Behring, Inc., West Sacramento, CA, USA) and by disk diffusion technique according to the CLSI criteria. ${ }^{7}$

\section{Statistical analysis}

Epi-Info version 3.2 software (Centers for Disease Control and Prevention, US) was used for data entry and descriptive statistical analysis. Categorical and continuous variables are presented as number and proportion, and median and range, respectively.

\section{Ethical considerations}

The study was approved by the Ethical Committee from the SESAB (Secretária de Saúde do Estado da Bahia). Written informed consent and verbal assent were obtained from each patient or children's parent or guardian and from all study participants, respectively.

\section{RESULTS}

During the study period, 146 patients ( 75 males, 71 females; mean age 14.5 years, ranging from 4 months to 77 years) were referred to the Referral Center for Cystic Fibrosis of Bahia, Hospital Otavio Mangabeira. A total of 369 biological samples (337 sputum and 32 oropharynx swabs) were analyzed and 279 bacterial strains were isolated and identified. The most frequent pathogens were S. aureus (35\%) and P. aeruginosa (21\%), with the highest rate of colonization observed in patients in the age group of 6 - 10 years and above 17 years old, respectively (Table 1).

In $35.6 \%$ of the samples analyzed, more than one microorganism were isolated, being the most frequent combination S. aureus and P. aeruginosa, found in 10\% (15 of 146) of the patients, while $85 \%$ (125 of 146) of the patients had only one pathogen identified in all cultured samples. During the study period only one patient, a 13year old boy, was chronically infected by Burkholderia cepacia complex, with positive cultures in all four samples collected monthly. This pathogen exhibited the mucoid phenotype and was highly susceptible to piperacillin, imipenem, aminoglycosides, and ciprofloxacin.

Table 1. Prevalence of pathogens identified from respiratory specimens in patients with cystic fibrosis, classified by age group $(n=146)$

\begin{tabular}{|c|c|c|c|c|c|c|c|c|c|c|c|}
\hline $\begin{array}{l}\text { Age } \\
\text { (years) }\end{array}$ & $\begin{array}{c}\mathrm{N}^{\mathrm{o}}(\%) \text { of } \\
\text { patients }\end{array}$ & S. aureus & $\begin{array}{c}\text { Non-mucoid } \\
\text { P. aerugi- } \\
\text { nosa }\end{array}$ & $\begin{array}{l}\text { Mucoid } \\
\text { P. aerugi- } \\
\text { nosa }\end{array}$ & $\begin{array}{c}\text { K. } \\
\text { pneumo- } \\
\text { niae }\end{array}$ & $\begin{array}{c}\text { H. } \\
\text { influen } \\
\text {-zae }\end{array}$ & $\begin{array}{c}\text { Acineto- } \\
\text { bacter } \\
\text { spp }\end{array}$ & $\begin{array}{c}\text { Alcali- } \\
\text { genes } \\
\text { spp }\end{array}$ & $\begin{array}{c}\text { Burkhol- } \\
\text { deria } \\
\text { sp }\end{array}$ & $\begin{array}{c}\text { S. } \\
\text { maltho- } \\
\text { philia }\end{array}$ & $\begin{array}{c}\text { Others } \\
\text { gram- } \\
\text { negative }\end{array}$ \\
\hline$\leq 1$ & $17(12 \%)$ & 7 & 1 & 1 & 5 & 2 & 0 & 0 & 0 & 1 & 6 \\
\hline $2-5$ & 28 (19\%) & 14 & 3 & 3 & 2 & 2 & 0 & 1 & 0 & 1 & 12 \\
\hline $6-10$ & $41(28 \%)$ & 29 & 0 & 5 & 2 & 1 & 1 & 0 & 0 & 0 & 15 \\
\hline $11-17$ & 28 (19\%) & 11 & 5 & 2 & 1 & 0 & 1 & 0 & 1 & 0 & 6 \\
\hline$\geq 17$ & 32 (22\%) & 12 & 8 & 6 & 2 & 2 & 2 & 2 & 0 & 1 & 10 \\
\hline Total & 146 & 73 & 34 & 17 & 12 & 7 & 4 & 3 & 1 & 3 & 49 \\
\hline
\end{tabular}


Table 2. Rate of susceptibility (\%) of mucoid and nonmucoid Pseudomonas aeruginosa isolates against different antimicrobial agents

\begin{tabular}{lcc}
\hline \multirow{2}{*}{$\begin{array}{l}\text { Antimicrobial } \\
\text { agents }\end{array}$} & \multicolumn{2}{c}{ Rate of susceptibility (\%) } \\
\cline { 2 - 3 } & $\begin{array}{c}\text { Non-Mucoid } \\
\text { aeruginosa (42) }\end{array}$ & $\begin{array}{c}\text { Mucoid } \\
\text { P. aeruginosa (17) }\end{array}$ \\
\hline Amikacin & 83 & 75 \\
\hline Aztreonam & 83 & 75 \\
\hline Ceftazidime & 79 & 75 \\
\hline Ciprofloxacin & 79 & 88 \\
\hline Gentamicin & 55 & 56 \\
\hline Imipenem & 100 & 88 \\
\hline Meropenem & 100 & 100 \\
\hline Piperacillin & 88 & 94 \\
\hline Tobramycin & 88 & 81 \\
\hline
\end{tabular}

Table 3. Rate of susceptibility (\%) of S. aureus isolates against different antimicrobial agents $(n=99)$

\begin{tabular}{lc}
\hline Antimicrobial agents & Rate of susceptibility (\%) \\
\hline Amoxicillin/clavulanate & 94 \\
\hline Cefazoline & 94 \\
\hline Ceftriaxone & 94 \\
\hline Ciprofloxacin & 90 \\
\hline Clindamycin & 90 \\
\hline Cotrimoxazole & 86 \\
\hline Erythromycin & 79 \\
\hline Gentamicin & 96 \\
\hline Rifampicin & 96 \\
\hline Linezolid & 100 \\
\hline Vancomycin & 100 \\
\hline
\end{tabular}

Susceptibility studies of $P$. aeruginosa over the study period are summarized in Table 2. In this population, nonmucoid $P$. aeruginosa isolates exhibited a much higher antimicrobial susceptibility than the mucoid strains, being fully susceptible to imepenem and meropenem. Both phenotypes were mainly gentamicin-resistant ( $45 \%$ and $44 \%)$, respectively.

Methicillin resistant Staphylococcus aureus (MRSA) was isolated from $6 \%$ of the patients. Among these, MRSA isolates showed no resistance against vancomycin, linezolid and rifampicin. Constitutive clindamycin resistance was detected in $10 \%$ of the isolates, and inducible clindamycin resistance was not identified in this study population. Rates of susceptibility of $S$. aureus are presented in Table 3 .

\section{DISCUSSION}

Colonization by pathogenic microorganisms in the respiratory tract of patients with CF occurs at young age and represents a serious health problem because it is considered a major cause of morbidity and mortality. ${ }^{1}$ As reported in previous studies on the prevalence and antimicrobial susceptibility of bacterial isolates from CF patients in USA, Germany, and South America, we found that Staphylococcus aureus and Pseudomonas aeruginosa are the most frequent pathogens in this population. ${ }^{8-13}$ The prevalence of S. aureus was highest (70.7\%) among children of 6 to 10 years of age. In older age group (11-17 and $>17$ years of age), the prevalence of $S$. aureus isolates declined as the prevalence of $P$. aeruginosa increased. However, $S$. aureus remained the most frequently isolated bacteria, regardless of patient age group.

Methicillin resistant S. aureus (MRSA) was isolated from eight patients $(6 \%)$ during our study, similar to the $5 \%$ reported in Germany. ${ }^{9}$ The rate of MRSA in comparison with the total amount of S. aureus isolates was $10 \%$. In contrast, a rate of methicillin resistance in CF patients as high as $18.8 \%$ was reported in the United States; ${ }^{13,14} 25.9 \%$ in Argentina; ${ }^{11}$ and $18 \%$ in Spain. Presumably, the differences in the MRSA rates in CF-patients correlate with the general nosocomial and community prevalence of MRSA of each country.

Pseudomonas aeruginosa producing metallo- $\beta$-lactamase (MBLs) was first reported in Japan in $1991,{ }^{15}$ and since then it has been described as associated with outbreaks of hospital-acquired infection in several countries. ${ }^{16-18}$ The first report of MBL-producing $P$. aeruginosa in CF patients was from Germany (5\%). ${ }^{9}$ In this study sample, we did not identify any MBL or ESBL-producing $P$. aeruginosa isolates. Although, ongoing surveillance of these multi-resistant strains is vital in public healthcare settings, allowing for the correct antimicrobial treatment of CF patients and the control of nosocomial infections through the implementation of suitable hygiene regimens.

Independently from the antimicrobial susceptibility, mucoid phenotypes of $P$. aeruginosa in CF respiratory samples represent a non-favorable prognostic aspect. ${ }^{1,19}$ In our study, mucoid $P$. aeruginosa isolates were observed in 12\% (17 of 146) of the patients and in all age groups, being the highest rate of colonization in the age group $>17$ years old. The non-mucoid $P$. aeruginosa isolates exhibited a much higher antimicrobial susceptibility than the mucoid ones.

However, some studies have shown that most patients with $P$. aeruginosa in the airways when clinically stable maintain the same strains of genotypes, when there are episodes of exacerbations. ${ }^{20}$

As caveat in interpreting these results cultures were taken only from patients clinically stable. However, some studies have shown that most patients with $P$. aeruginosa in their airways when clinically stable maintain the same strain genotypes when episodes of exacerbations occur. ${ }^{20}$ Therefore, initial antibiotic therapy of an exacerbation of CF is usually 
determined by the results of antibiotic susceptibility testing performed on isolates recovered from the most recent culture of that patient. ${ }^{1}$

This study was also limited by the short follow-up period and because the small number of some groups of patients infected with individual strains did not allow for correlating microbiological data to clinical outcomes between groups of patients. Our data emphasize the crucial role of microbiological methods in defining possible therapeutic strategies that may help guiding antibiotic therapy regimens in $\mathrm{CF}$ patients. Further research is therefore needed to determine whether the bacteria repertoire in the clinical stable phase is the same during the exacerbation phase.

\section{ACKNOWLEDGEMENTS}

We thank the clinical and laboratory staff of Hospital Otávio Mangabeira for their cooperation, and the patients and their families.

\section{REFERENCES}

1. Ratjen FA. Cystic fibrosis: pathogenesis and future treatment strategies. Respir Care 2009; 54:595-605.

2. Boucher RC. New concepts of the pathogenesis of cystic fibrosis lung disease. Eur Respir J 2004; 23:146-58.

3. Saiman L, Siegel J. Infection control in cystic fibrosis. Clin Microbiol Rev 2004; 17:57-71.

4. Rajan S, Saiman L. Pulmonary infections in patients with cystic fibrosis. Semin Respir Infect 2002; 17:47-56.

5. O'Sullivan BP, Freedman SD. Cystic fibrosis. Lancet 2009; 373:1891-904.

6. Rosenstein BJ, Cutting GR. The diagnosis of cystic fibrosis: a consensus statement. Cystic Fibrosis Foundation Consensus Panel. J Pediatr 1998; 132:589-95.

7. CLSI. Performance standards for antimicrobial susceptibility testing, in Seventeenth Informational Supplement. 2007, Approved Standard M100-S17: Wayne, PA.

8. Lambiase A, Raia V, Del Pezzo M, Sepe A, Carnovale V, Rossano F. Microbiology of airway disease in a cohort of patients with cystic fibrosis. BMC Infect Dis 2006; 6:4.
9. Valenza G, Tappe D, Turnwald D et al. Prevalence and antimicrobial susceptibility of microorganisms isolated from sputa of patients with cystic fibrosis. J Cyst Fibros 2008; 7:123-7.

10. Santana MA, Matos E, do Socorro Fontoura M, Franco R Barreto D, Lemos AC. Prevalence of pathogens incystic fibrosis patients in Bahia, Brazil. Braz J Infect Dis, 2003; 7:69-72.

11. Anzaudo MM, Busquets NP, Ronchi S, Mayoral C. Isolated pathogen microorganisms in respiratory samples from children with cystic fibrosis. Rev Argent Microbiol 2005; 37:129-34.

12. García, AD, Ibarra A, Rodríguez FC, Casal M. Antimicrobial susceptibility of bacterial isolates from patients with cystic fibrosis. Rev Esp Quimioter 2004; 17:332-5.

13. Razvi S, Quittell L, Sewal A, Quinton H, Marshall B, Saiman L. Respiratory microbiology of patients with cystic fibrosis in the United States, 1995-2005. Chest, 2009.

14. Burns JL, Emerson J, Stapp JR et al. Microbiology of sputum from patients at cystic fibrosis centers in the United States. Clin Infect Dis 1998; 27:158-63.

15. Nishio H, Komatsu M, Shibata N et al. Metallo-beta-lactamase-producing gram-negative bacilli: laboratory-based surveillance in cooperation with 13 clinical laboratories in the Kinki region of Japan. J Clin Microbiol 2004; 42:5256-63.

16. Lauretti L, Riccio ML, Mazzarol A et al. Cloning and characterization of blaVIM, a new integron-borne metallo-betalactamase gene from a Pseudomonas aeruginosa clinical isolate. Antimicrob Agents Chemother 1999; 43:1584-90.

17. Gales AC, Menezes LC, Silbert S, Sader HS. Dissemination in distinct Brazilian regions of an epidemic carbapenem-resistant Pseudomonas aeruginosa producing SPM metallo-betalactamase. J Antimicrob Chemother 2003; 52:699-702.

18. Gales AC, Menezes LC, Silbert S, Sader HS. Dissemination in distinct Brazilian regions of an epidemic carbapenem-resistant Pseudomonas aeruginosa producing SPM metallo-betalactamase. J Antimicrob Chemother 2003; 52:699-702.

19. Stewart PS, Rayner J, Roe F, Rees WM. Biofilm penetration and disinfection efficacy of alkaline hypochlorite and chlorosulfamates. J Appl Microbiol 2001; 91:525-32.

20. Aaron SD, Ramotar K, Ferris W et al. Adult cystic fibrosis exacerbations and new strains of Pseudomonas aeruginosa. Am J Respir Crit Care Med 2004; 169:811-5. 